\title{
Clinicopathological predictors of chemoresponsiveness in epithelial ovarian cancer: a preliminary institutional study
}

\author{
Rebecca K Chung, BS, ${ }^{1}$ Andreea Mihai Newtson, MD, ${ }^{2}$ Sarah L Mott, MS, ${ }^{3}$ Jesus \\ Gonzalez Bosquet, MD, PhD²
}

Keywords: Epithelial ovarian cancer, survival, response to treatment, clinical factors, pathological factors, CA125

\begin{abstract}
Objective: One-third of women with epithelial ovarian cancer are resistant to standard platinum-based chemotherapy, and insufficient data exist in predicting response to chemotherapy. We describe the clinical and pathological factors of patients with complete and incomplete response to treatment.
\end{abstract}

Method: In this retrospective study, data was reviewed from 75 medical charts of 243 patients with primary epithelial ovarian cancers as a preliminary study. All patients underwent chemotherapy and cytoreductive surgery for primary disease. Fifty-six patients had complete response (CR) to chemotherapy and $19 \mathrm{had}$ incomplete response (IR). Fifty-eight and 17 patients had optimal and suboptimal cytoreductive surgery, respectively. Clinical and pathological factors were compared in patients with complete and incomplete response to treatment, and optimal and suboptimal surgery. Overall survival (OS), cancer-specific survival (CSS), and time to recurrence (TTR) were estimated using the Kaplan-Meier method for patient groups.

Results: The majority of patients in both the CR and IR groups were diagnosed at advanced stage ovarian cancer. The CR group had significantly lower preoperative CA125 and was more likely to have optimal chemotherapy. The CR group was also more likely to have lymph nodes removed during cytoreductive surgery. A significantly lower percentage of $C R$ patients died from the disease and had statistically longer disease free survival. Patients who underwent suboptimal surgery had significantly shorter survival, but no difference existed in the time until recurrence between patients with optimal and suboptimal surgery. OS, CSS, and TTR were significantly increased in the $C R$ group and in patients that had optimal surgery.

Conclusion: Complete response during treatment and optimal surgery significantly increases OS, CSS, and TTR. Preoperative CA125 and lymph node removal during surgery may be predictive of complete treatment response.

${ }^{1}$ University of lowa, Roy J. and Lucille A. Carver College of Medicine, lowa City, lowa

${ }^{2}$ University of lowa Hospitals and Clinics, Department of Obstetrics and Gynecology, lowa City, lowa

${ }^{3}$ Holden Comprehensive Cancer Center, University of lowa, lowa City, lowa

Please cite this paper as: Chung RK, Mihai Newtson A, Mott SL, Gonzalez Bosquet J. Clinicopathological predictors of chemoresponsiveness in epithelial ovarian cancer: a preliminary institutional study. Proceedings in Obstetrics and Gynecology, 2015;5(2):Article 6 [ 13 p.]. Available from: http://ir.uiowa.edu/pog/ Free full text article.

Corresponding author: Rebecca K Chung, Roy J. and Lucille A. Carver College of Medicine, University of lowa, 200 Hawkins Drive, lowa City, lowa 52242, rebecca-chung@uiowa.edu

Financial Disclosure: The authors report no conflict of interest.

Copyright: (c) 2015 Chung et al. This is an open-access article distributed under the terms of the Creative Commons Attribution License, which permits unrestricted use, distribution, and reproduction in any medium, provided the original author and source are credited. 


\section{Introduction}

The incidence of ovarian cancer has decreased since the 1980s; nevertheless, it remains the second leading cause of malignancy in women and the leading cause of mortality from gynecologic cancers. Approximately $90 \%$ of ovarian cancers are epithelial in nature and about $70 \%$ are diagnosed at advanced stage defined as International Federation of Gynecology and Obstetrics (FIGO) stage III and IV. Advanced stage ovarian cancer is associated with poor prognosis and a 5year survival rate of $27 \%{ }^{1}$

The standard treatment plan for primary epithelial ovarian cancer (EOC) includes debulking surgery and platinum-based chemotherapy. Surgery is an important mainstay of treatment and has been shown to improve patients' chemoresponsiveness and survival. ${ }^{2,3}$ However, one-third of women are resistant to platinum-based therapy, defined as having evidence of disease within 6 months of treatment. Additionally, they have worse progression-free and overall survival. Up to $85 \%$ of advanced stage EOC relapse, and the median time until recurrence is 18 months. $^{4}$

The current literature contains unsatisfactory data to identify differences between patients who are responsive and nonresponsive to standard chemotherapy. Therefore, the purpose of this study is to describe the clinical and pathological characteristics of patients with complete and incomplete response to treatment. This can potentially determine possible predictors of response. Identifying these predictors of chemoresponsiveness will be integral in individualizing treatment and solving the issue of chemoresistance.

\section{Materials and Methods}

\section{Study design}

Patients with primary epithelial ovarian cancers diagnosed by tumor histological analysis and treated at the Department of Gynecologic Oncology at the University of lowa Hospital and Clinics from January 1991 to December 2013 were eligible for inclusion in this retrospective study. All patients underwent chemotherapy and surgical cytoreduction for primary disease.

Institutional Review Board approval was obtained and a total of 243 patients were eligible for this study. Data was collected from medical charts of 75 patients (median age of 59 years ranging from 25 - 83 years) during July 27, 2015 to August 21, 2015 as a preliminary study to determine the viability of this research. Fifty-six patients had complete response and 19 had incomplete response to treatment, defined as evidence of disease within 6 months. Fifty-eight patients had optimal cytoreductive surgery and 17 had suboptimal surgery. Forty-nine (65.3\%) patients had recurrence of disease, and $58(77.3 \%)$ patients died. Clinical and pathology findings included age at diagnosis, body mass index, Charlson comorbidity index, FIGO stage, tumor cell type, tumor grade, preoperative CA125, imaging modality at diagnosis, and tumor location (Table 1). Imaging modalities used were CT, ultrasound, MRI, and PET scans. None of the 
patients in this cohort received PET scans, 2 had MRIs and 11 had none of the four options. These patients were included under "other." Treatment data included chemotherapy drug, number of cycles, removal of pelvic or para-aortic nodes at surgery, and whether the patient received optimal treatment (Table 2).

Patient outcome was assessed by vital status, tumor status, time until recurrence, and time until death (Tables 3-4). The Kaplan-Meier method was used to construct survival curves for overall survival (OS), cancer-specific survival (CSS), and time to recurrence (TTR) (Figure 1). For OS, time was calculated from date of surgery to death. Patients still alive were censored at date of last contact. For CSS, time was calculated from date of surgery to date of death due to disease. Patients still alive or having died from other causes were censored at date of last contact or death. respectively. For TTR, time was calculated from date of surgery to first relapse. If a patient did not experience a relapse, they were considered censored at date of last contact.

\section{Statistical Analysis}

To investigate treatment response and cytoreduction surgery differences in demographic, clinicopathologic, and outcome variables, chi-squared and ttests (Fisher's exact and Wilcoxon rank sum tests where appropriate) were used. The Kaplan-Meier method was used to construct survival curves for overall survival (OS), cancer-specific survival (CSS), and time to recurrence (TTR) as aforementioned. The log-rank test was performed to assess for differences between treatment response and cytoreduction surgery. All statistical testing was two-sided and assessed for significance at the $5 \%$ level using SAS v9.4 (SAS Institute, Cary, NC).

\section{Results}

Characteristics of patients with complete and incomplete response to chemotherapy

This study included 75 patients, and the clinical characteristics and pathology findings of these patients are found in Table 1. Fifty-six (74.7\%) patients had complete response (CR) and 19 (25.3\%) had incomplete response (IR) to chemotherapy. At diagnosis, patients had a mean age of $58.3 \pm 12.9$ years, median body mass index of 26 (range: 16.5-47.8), and median Charlson index of 5 (range: 1-10). A significant difference was evidenced between treatment response and preoperative CA125. More specifically, patients achieving a CR had lower median preoperative CA125 levels compared to those with an IR (362.5 U/mL vs. 771.0 $\mathrm{U} / \mathrm{mL} ; \mathrm{p}=0.03$ ). One patient had a preoperative CA125 of $588,741 \mathrm{U} / \mathrm{mL}$, a significant outlier, and was excluded from the analysis. 
Proceedings in Obstetrics and Gynecology, 2015;5(2):6

Table 1. Clinical and pathological characteristics of treatment responses

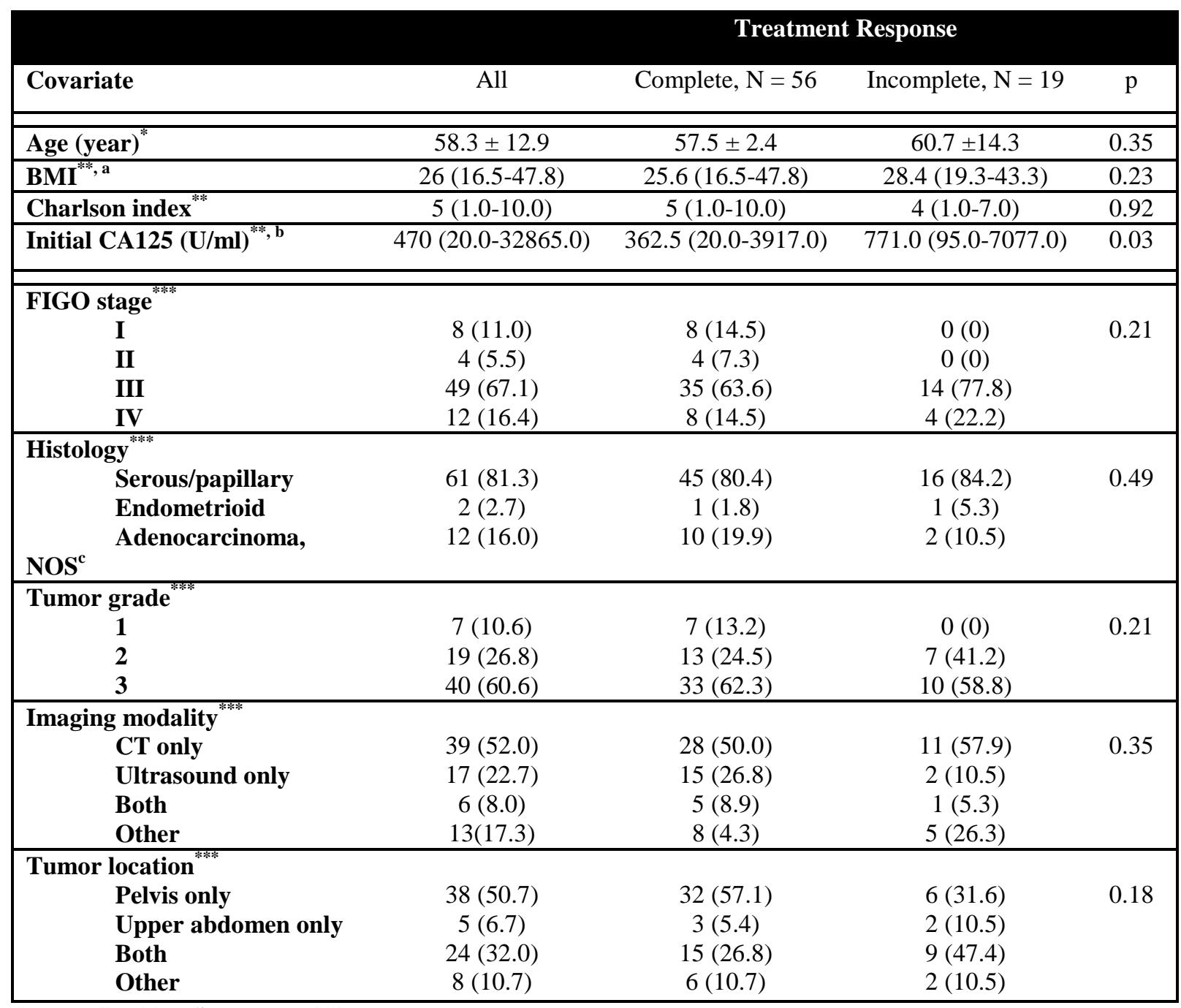

*mean $\pm \mathrm{SD}, * *$ median (range), ***N (\%)

${ }^{a} N=55$; complete response $(C R)=44$, incomplete response $(I R)=11$

${ }^{b} \mathrm{~N}=70 ; \mathrm{CR}=52, \mathrm{IR}=18$

${ }^{c}$ NOS, not otherwise specified

The majority of patients were diagnosed at advanced stage disease. Sixty-one $(81.3 \%)$ patients were diagnosed at FIGO stage III or IV, and $40(60.6 \%)$ patients had tumor grade 3 . No patients with incomplete response to treatment were diagnosed in stage I or II. However, FIGO staging, tumor cell type, tumor grade, imaging modality used at diagnosis, and tumor location were not significantly related to chemotherapy response.

In terms of treatment as outlined in Table 2, both CR and IR groups had a median of 6 cycles of chemotherapy. 
Most patients were predictably treated with carboplatin and/or paclitaxel. A significantly greater frequency of patients who achieved CR had optimal treatment $(60.7 \%$ vs. $26.3 \% ; p<0.01)$, and had pelvic and/or para-aortic lymph nodes removed during surgery $(35.7 \%$ vs. $10.5 \% ; p=0.04)$. The involvement of bowel during surgery, the achievement of optimal cytoreduction, and the type of chemotherapy drug showed no statistically significant differences between CR and IR groups.

Table 2. Chemotherapy and surgery treatment types

\begin{tabular}{|c|c|c|c|}
\hline \multirow[b]{2}{*}{ Covariate } & \multicolumn{2}{|c|}{ Treatment Response } & \multirow[b]{2}{*}{$\mathbf{P}$} \\
\hline & Complete, $\mathrm{N}=56$ & Incomplete, $\mathrm{N}=19$ & \\
\hline Number of cycles ${ }^{\star *}$ & $6(0-18)$ & $6(1-10)$ & 0.74 \\
\hline Optimal chemotherapy* & $34(60.7)$ & $5(26.3)$ & $<0.01$ \\
\hline \multicolumn{4}{|l|}{ Chemotherapy drug ${ }^{\text {*xx }}$} \\
\hline Carboplatin & $44(78.6)$ & $15(78.9)$ & 1.00 \\
\hline Paclitaxel & $46(82.1)$ & $13(68.4)$ & 0.21 \\
\hline Cisplatinum & $8(14.3)$ & $3(15.8)$ & 1.00 \\
\hline Other & $16(28.6)$ & $8(42.1)$ & 0.27 \\
\hline Optimal cytoreductive surgery ${ }^{* \star x}$ & $45(80.4)$ & $13(68.4)$ & 0.34 \\
\hline \multicolumn{4}{|l|}{ Areas of surgery ${ }^{* \star}$} \\
\hline Lymph nodes & $20(35.7)$ & $2(10.5)$ & 0.04 \\
\hline Bowel & $18(32.1)$ & $5(26.3)$ & 0.63 \\
\hline
\end{tabular}

mean $\pm S D$, "median (range), " $N(\%)$

Association of patient outcomes with chemotherapy response and cytoreductive surgery

Outcomes of patients in both $\mathrm{CR}$ and IR groups are represented in Table 3. 18 $(94.7 \%)$ patients with IR had tumor present after primary therapy. Significantly less patients with CR (57.1\%) than those with IR $(94.7 \%)$ had tumor present after therapy $(p<0.01)$.

In both $\mathrm{CR}$ and IR groups, the majority of patients died from ovarian cancer. However, significantly more patients with IR died from the disease than patients who had CR $(94.7 \%$ vs. $56.4 \%$, $p<0.01$ ). More patients in the CR group are alive or dead from causes other than ovarian cancer $(p<0.01)$. Thirty-five
(62.5\%) patients with $\mathrm{CR}$ had recurrence of disease and a median time to recurrence of 18.7 months (range: 8.9-81.5). The majority (73.6\%) of patients with IR had recurrence; however the median time was 6.9 months (range 4.3-28.6). Patients in CR group had a longer time until first recurrence of disease than the IR group $(p<0.01)$. Additionally, the survival was significantly longer for patients with $\mathrm{CR}$ than patients with IR $(p<0.01)$.

Regarding surgical treatment, 58 (77.3\%) and 17 (22.7\%) patients had optimal (OPS) and suboptimal (SOS) cytoreductive surgery, respectively, as shown in Table 4. The majority had tumor present after primary therapy for both groups. Nevertheless, significantly 
more patients who underwent SOS (94.1\%) had tumor present compared to patients who had OPS $(58.6 \%, p<$ $0.01)$. Also, more patients in the OPS group had no evidence of disease compared to patients in the SOS group $(41.4 \%$ vs. $5.9 \% ; p<0.01)$.

Most patients died from the disease; however, less patients died due to the disease in the OPS group than the SOS group $(57.9 \%$ vs. $94.1 \%$; $p<0.02)$. Patients who had OPS were significantly more likely to be alive $(28.1 \%$ vs. $5.9 \%$; $p=0.02)$ or died from other causes $(14.0 \%$ vs. $0 \% ; p<0.02)$ than patients who had SOS. Patients with OPS also had significantly longer survival (39.5 vs. 22.0 months; $p<0.05)$.

Table 3. Outcome of patients with complete versus incomplete response

\begin{tabular}{|c|c|c|c|}
\hline \multicolumn{4}{|c|}{ Treatment Response } \\
\hline Covariate & Complete, $\mathrm{N}=56$ & Incomplete, $\mathbf{N}=19$ & $\mathbf{P}$ \\
\hline Tumor status & & & $<0.01$ \\
\hline No evidence of disease & $24(2.9)$ & $1(5.9)$ & \\
\hline Tumor present & $32(57.1)$ & $18(94.7)$ & \\
\hline Vital status $^{\text {**x }}$ & & & $<0.01$ \\
\hline Alive & $16(29.1)$ & $1(5.3)$ & \\
\hline Dead from disease & $31(56.4)$ & $18(94.7)$ & \\
\hline Dead from other & $8(14.5)$ & $0(0)$ & \\
\hline Time until recurrence (months) ${ }^{* *}$ a & $18.7(8.9-81.5)$ & $6.9(4.3-28.6)$ & $<0.01$ \\
\hline Time until death (months) ${ }^{* x}, \mathrm{~b}$ & $50.1(1.2-191.3)$ & $14.9(1.9-48.9)$ & $<0.01$ \\
\hline
\end{tabular}

${ }^{*}$ mean $\pm S D,{ }^{\star \star}$ median (range), ${ }^{\star \star \star} N(\%)$

${ }^{a} N=49 ; C R=35, I R=14$

${ }^{b} N=58 ; C R=40, I R=18$

Table 4. Outcome of patients with optimal versus suboptimal surgery

\begin{tabular}{|c|c|c|c|}
\hline \multirow[b]{2}{*}{ Covariate } & \multicolumn{2}{|c|}{ Surgery } & \multirow[b]{2}{*}{$\mathbf{P}$} \\
\hline & Optimal, N = 58 & Suboptimal, N = 17 & \\
\hline \multicolumn{4}{|l|}{ Tumor status $^{\star \star *}$} \\
\hline No evidence of disease & $24(41.4)$ & $1(5.9)$ & $<.01$ \\
\hline Tumor present & $34(58.6)$ & $16(94.1)$ & \\
\hline \multicolumn{4}{|l|}{ Vital status $^{* \star *}$} \\
\hline Alive & $16(28.1)$ & $1(5.9)$ & 0.02 \\
\hline Dead from disease & 33 (57.9) & $16(94.1)$ & \\
\hline Dead from other & $8(14)$ & $0(0)$ & \\
\hline Time until recurrence (months) ${ }^{* *}$ a & $14.7(4.3-70.7)$ & $14.4(6.3-81.5)$ & 0.84 \\
\hline Time until death (months) ${ }^{* x, b}$ & $39.5(1.5-191.3)$ & $22.0(1.2-118.4)$ & 0.05 \\
\hline
\end{tabular}

${ }^{*}$ mean $\pm S D,{ }^{\star \star}$ median (range), ${ }^{\star \star \star} N(\%)$

${ }^{a} N=48 ;$ optimal $=33$, suboptimal $=15$

${ }^{b} \mathrm{~N}=58 ;$ optimal $=42$, suboptimal $=16$ 


\section{Survival analysis}

The Kaplan-Meier analyses to assess overall survival (OS), cancer-specific survival (CSS), and time to recurrence (TTR) are shown in Figures 1 and 2, and Tables 5 and 6. Patients who had

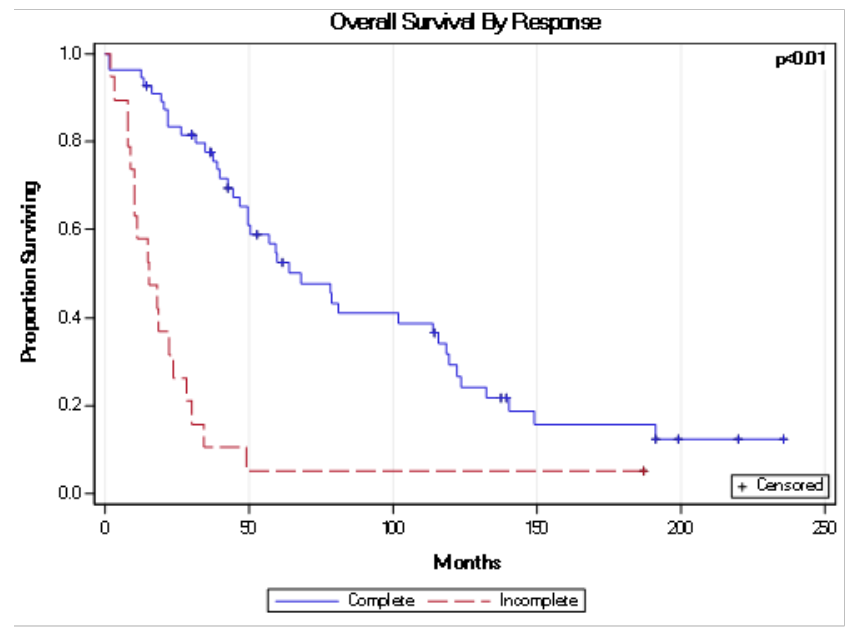

complete treatment response had significantly increased OS, CSS, and TTR ( $p<0.01$ for all). Patients who had optimal surgery also had significantly higher OS, CSS, and TTR than patients with suboptimal surgery $(p<0.01$ for all).
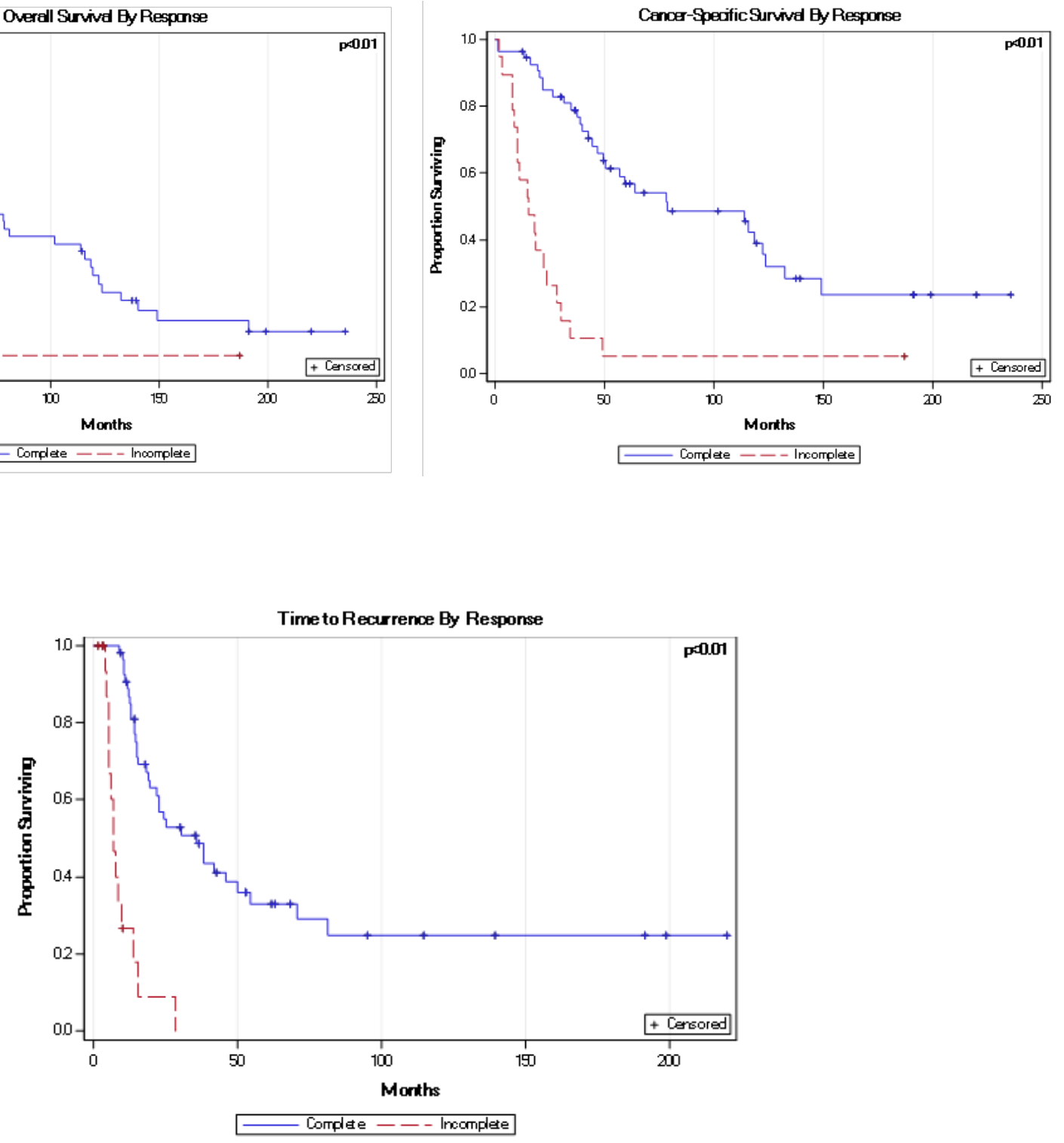

Figure 1. Kaplan-Meier analysis of overall survival, cancer-specific survival, and time to recurrence between patients with complete and incomplete response to treatment. Significant difference exists between both groups in all three categories $(p<0.01)$, and median time of survival is presented in Table 5. 
Table 5. Survival analysis for patients with complete and incomplete response

\begin{tabular}{|lccc|}
\multicolumn{2}{c|}{ Treatment response } & P \\
\hline Median time (months) & Complete & Incomplete & $<\mathbf{0 1}$ \\
\hline Overall survival & 68 & 15 & $<\mathbf{0 . 0 1}$ \\
\hline Cancer specific survival & 79 & 15 & $<\mathbf{0 1}$ \\
\hline Time to recurrence & 36 & 7 & \\
\hline
\end{tabular}
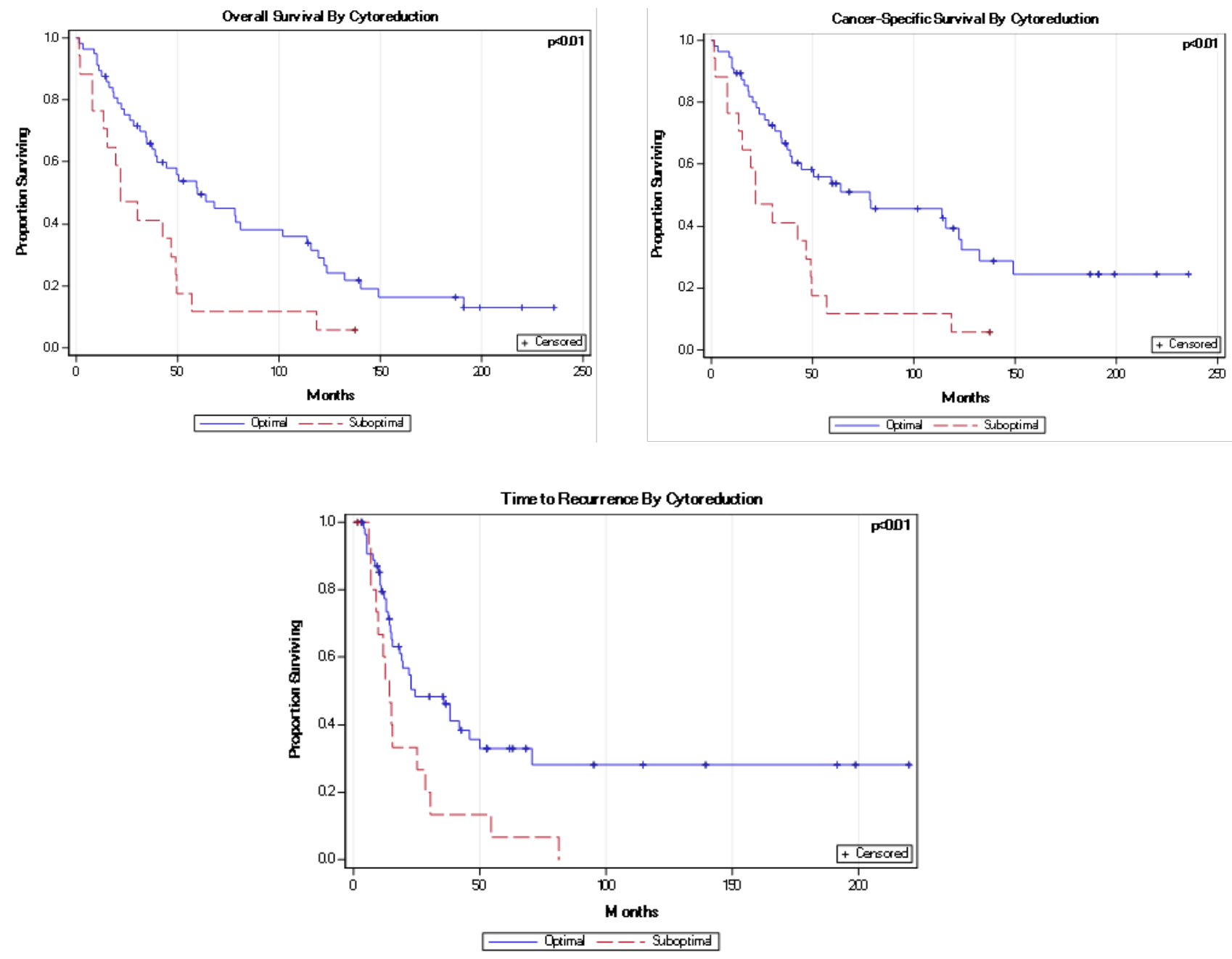

Figure 2. Kaplan-Meier analysis of overall survival, cancer-specific survival, and time to recurrence between patients with optimal and suboptimal surgery. Significant difference exists between both groups in all three categories $(p<$ 0.01), and median time of survival is presented in Table 6. 
Proceedings in Obstetrics and Gynecology, 2015;5(2):6

Table 6. Survival analysis for patients with optimal and suboptimal surgery

\begin{tabular}{|lccc|}
\hline \multicolumn{3}{c|}{ Surgery } \\
\hline Median time (months) & Optimal & Suboptimal & P \\
\hline Overall survival & 60 & 22 & $<0.01$ \\
\hline Cancer-specific survival & 78 & 22 & $<0.01$ \\
\hline Time to recurrence & 24 & 14 & $<0.01$ \\
\hline
\end{tabular}

\section{Discussion}

Standard treatment of epithelial ovarian cancer is primary debulking surgery in conjunction with platinum-based chemotherapy. Despite the success of chemotherapy, about one-third of women are either refractory or resistant to treatment. Preoperative CA125 and lymph node removal during surgery were associated with complete treatment response in this preliminary institutional study.

\section{CA125 as a predictor of chemotherapy} response

CA125 is a biomarker of epithelial tumors that is useful as a measure for monitoring treatment effectiveness and disease recurrence. It is not recommended as a tool for screening. In our study, preoperative CA125 is a significant predictor of chemotherapy response. Patients with complete response to treatment had significantly lower CA125 at diagnosis, and complete response to treatment had significantly greater overall survival, cancer-specific survival, and time to recurrence. Many studies both support and contradict this finding. A study by Oikonomopoulou et al. agrees that lower baseline CA125 prior to chemotherapy is associated with better chemotherapy response. Higher baseline values had worse OS and PFS. ${ }^{5}$ Similarly, Palmer et al. and Juretzka et al. found lower CA125 were more significantly associated with longer overall survival and progression-free survival. ${ }^{6,7}$ Serum CA125 levels correlate with vascular endothelial growth factor (VEGF) expression, which is significantly upregulated in epithelial ovarian cancer, and predicts positive responsiveness to platinum-based chemotherapy. ${ }^{8}$

The debate continues as other studies discovered no correlation between preoperative CA125, chemotherapy response, and surgical outcome despite being a validated marker for disease status during chemotherapy., ${ }^{8,9,10}$ The role of CA125 as a predictor marker for chemoresponsiveness may be appropriate with newer chemotherapy. Collinson et al. suggests that CA125 can identify patients with epithelial ovarian cancer who will likely respond to bevacizumab. ${ }^{11}$ When patients are treated with standard chemotherapy and bevacizumab concurrently and then via maintenance, patient with high CA125 and ascites have improved overall survival and progression-free survival than patients with lower CA125 and without ascites. ${ }^{12}$ Albeit higher levels of CA125 are associated with worse patient outcome, the threshold value or 
range to determine which patients are at increased risk for incomplete response to chemotherapy is unknown.

Complete chemotherapy response and optimal surgery in controlling disease

Complete response to therapy and optimal cytoreductive surgery are two important factors associated with a decrease in death from disease and longer survival. Over $94 \%$ of patients with either incomplete treatment response or suboptimal surgery died from ovarian cancer. This value lowered significantly to less than $60 \%$ death from disease those with either complete treatment response or optimal surgery. Additionally, patients with complete treatment or optimal surgery had longer time until death and recurrence, greater overall survival, and greater cancerspecific survival of up to over 5-fold increase. The increase in median survival time and time to recurrence was greater in terms of chemotherapy response than for surgery. Although both surgery and chemotherapy are key components to treating ovarian cancer, this suggests that chemotherapy has a greater role in prolonging survival and recurrence.

Our study also found that patients with complete response to therapy were more likely to have either pelvic and/or para-aortic lymph nodes removed during surgery. The spread of disease to the retroperitoneal lymph nodes is a prominent characteristic of advanced stage ovarian cancer. Although FIGO stage did not differ between the response groups, patients with complete treatment response more frequently had surgery to the nodal areas than patients with an incomplete response. Involvement of the bowel during surgery showed no significant associations with the two response groups. In a recent review by Chang et al. discussing cytoreduction on advanced stage ovarian cancer, aggressive surgery is prognostic of better outcomes, but optimal debulking is dependent on expertise of the surgeon and of the institution. ${ }^{13}$ This study was completed at a teaching hospital with a department of gynecologic oncology and specialized surgeons. Therefore, these findings may be specific to this institution.

\section{Limitations}

The limitations of this study are due to the retrospective nature of the analysis. Additionally, there may be not sufficient power to establish significances in this preliminary analysis. The incomplete response group represented $25.3 \%$ of the patient sample and the suboptimal surgery group represented $22.7 \%$. Thus, the power should increase as more patients are added to this study.

\section{Future direction}

The current conflicting clinicopathological data pushes us to look deeper into genomic factors that may help us better understand how to predict chemoresponsiveness. In future studies, we will look at possible molecular predictors. The existing literature has assessed the predictive value of tumor markers such as human epididymis protein 4 (HE4), a glycoprotein overexpressed in serous and endometrioid ovarian cancers. Serum HE4 levels were not found to be a predictor of chemoresponse prior to 
treatment, but its normalization during treatment was significantly associated with positive outcomes. ${ }^{9,14}$ More recently, Muallem et al. found that the level of ERCC1, a DNA excision repair protein, was significantly associated with better overall survival. Patients who did not respond to platinum-based chemotherapy with low or intermediate ERCC1 levels had a longer overall survival than non-responders with high ERCC $1 .{ }^{15}$ Steffensen et al. furthermore suggest that high ERCC1 expression is associated with earlier time to recurrence and platinum-resistance. ${ }^{16}$ Lastly, other proteins, such as Ecadherin, interferon regularly factor 1 (IRF1), and high-temperature-required protein A2 (HtrA2) have been shown to be prognostic and associated with increased response to platinum-based chemotherapy at higher levels of expression. ${ }^{17,18,19}$ These specific proteins may be subjects of future evaluation in this institutional study.

\section{References}

1. American Cancer Society. Cancer Facts \& Figures 2015. Atlanta: American Cancer Society; 2015. Accessed June 21, 2015. http://www.cancer.org/research/cancerfa ctsstatistics/allcancerfactsfigures/index.

2. American Cancer Society. Ovarian Cancer. Atlanta: American Cancer Society; 2015. Access June 21, 2015. http://www.cancer.org/cancer/ovarianca ncer/detailedguide/index.

3. Jayson GC, Kohn EC, Kitchener HC, Ledermann JA. Ovarian cancer. Lancet. 2014 Oct 11;384(9951):1376-88. doi: 10.1016/S0140-6736(13)62146-7. Epub 2014 Apr 21. PubMed PMID: 24767708.
4. Petrillo M, Zannoni GF, Tortorella L, Pedone Anchora L, Salutari V, Ercoli A, Margariti PA, Scambia G, Fagotti A. Prognostic role and predictors of complete pathologic response to neoadjuvant chemotherapy in primary unresectable ovarian cancer. Am J Obstet Gynecol. 2014 Dec;211(6):632.e1-8. doi: 10.1016/j.ajog.2014.06.034. Epub 2014 Jun 19. PubMed PMID: 24954656.

5. Oikonomopoulou K, Li L, Zheng $\mathrm{Y}$, Simon I, Wolfert RL, Valik D, Nekulova $M$, Simickova $M$, Frgala $T$, Diamandis EP. Prediction of ovarian cancer prognosis and response to chemotherapy by a serum-based multiparametric biomarker panel. $\mathrm{Br} \mathrm{J}$ Cancer. 2008 Oct 7;99(7):1103-13. doi: 10.1038/sj.bjc.6604630. Epub 2008 Sep 2. PubMed PMID: 18766180.

6. Palmer JE, Sant Cassia LJ, Irwin CJ, Morris AG, Rollason TP. The prognostic value of nuclear morphometric analysis in serous ovarian carcinoma. Int $\mathrm{J}$ Gynecol Cancer. 2008 JulAug;18(4):692-701. Epub 2007 Oct 18. http://dx.doi.org/10.1111/j.15251438.2007.01093.x PubMed PMID: 17944918.

7. Juretzka MM, Barakat RR, Chi DS, Iasonos A, Dupont J, Abu-Rustum NR, Poynor EA, Aghajanian C, Spriggs D, Hensley ML, Sabbatini P. CA125 level as a predictor of progression-free survival and overall survival in ovarian cancer patients with surgically defined disease status prior to the initiation of intraperitoneal consolidation therapy. Gynecol Oncol. 2007 Jan;104(1):17680. Epub 2006 Sep 25. doi:10.1016/j.ygyno.2006.07.027 PubMed PMID: 16996584. 
8. Masoumi-Moghaddam S, Amini A, Wei AQ, Robertson G, Morris DL. Vascular endothelial growth factor expression correlates with serum CA125 and represents a useful tool in prediction of refractoriness to platinum-based chemotherapy and ascites formation in epithelial ovarian cancer. Oncotarget. 2015 Jun 10. [Epub ahead of print] PubMed PMID: 26143638.

9. Vallius $\mathrm{T}$, Hynninen $\mathrm{J}$, Auranen $\mathrm{A}$, Carpén O, Matomäki J, Oksa $\mathrm{S}$, Virtanen J, Grénman S. Serum HE4 and CA125 as predictors of response and outcome during neoadjuvant chemotherapy of advanced high-grade serous ovarian cancer. Tumour Biol. 2014 Dec;35(12):12389-95. doi: 10.1007/s13277-014-2553-1. Epub 2014 Sep 5. PubMed PMID: 25190018.

10. Yildirim Y, Ertas IE, Dogan A, Gultekin OE, Gultekin E. The predictors of response to neoadjuvant chemotherapy in advanced epithelial ovarian cancer. J Surg Oncol. 2012 Feb;105(2):200-5. doi: 10.1002/jso.22053. Epub 2011 Aug 3. PubMed PMID: 21815151.

11. Collinson $F$, Hutchinson $M$, Craven RA, Cairns DA, Zougman A, Wind TC, Gahir $\mathrm{N}$, Messenger MP, Jackson $\mathrm{S}$, Thompson D, Adusei C, Ledermann JA, Hall G, Jayson GC, Selby PJ, Banks RE. Predicting response to bevacizumab in ovarian cancer: a panel of potential biomarkers informing treatment selection. Clin Cancer Res. 2013 Sep 15;19(18):5227-39. doi: 10.1158/1078-0432.CCR-13-0489. Epub 2013 Aug 9. PubMed PMID: 23935036.
12. Ferriss JS, Java JJ, Bookman MA, Fleming GF, Monk BJ, LWalker J, Homesley HD, Fowler J, Greer BE, Boente MP, Burger RA. Ascites predicts treatment benefit of bevacizumab in front-line therapy of advanced epithelial ovarian, fallopian tube and peritoneal cancers: An NRG Oncology/GOG study. Gynecol Oncol. 2015 Jul 26. pii: S00908258(15)30088-3. doi: 10.1016/j.ygyno.2015.07.103. [Epub ahead of print] PubMed PMID: 26216729.

13. Chang SJ, Bristow RE, Chi DS, Cliby WA. Role of aggressive surgical cytoreduction in advanced ovarian cancer. J Gynecol Oncol. 2015 Jul 17. [Epub ahead of print] PubMed PMID: 26197773.

14. Angioli R, Capriglione S, Aloisi A, Guzzo F, Luvero D, Miranda A, Damiani P, Montera R, Terranova C, Plotti F. Can HE4 predict platinum response during first-line chemotherapy in ovarian cancer? Tumour Biol. 2014 Jul;35(7):7009-15. doi: 10.1007/s13277014-1836-x. Epub 2014 Apr 21. PubMed PMID: 24748235.

15. Muallem MZ, Braicu I, Nassir M, Richter R, Sehouli J, Arsenic R. ERCC1 expression as a predictor of resistance to platinum-based chemotherapy in primary ovarian cancer. Anticancer Res. 2014 Jan;34(1):393-9. PubMed PMID: 24403493.

16. Steffensen KD, Smoter $M$, Waldstrøm M, Grala B, Bodnar L, Stec R, Szczylik C, Jakobsen A. Resistance to first line platinum paclitaxel chemotherapy in serous epithelial ovarian cancer: the prediction value of ERCC1 and Tau expression. Int J Oncol. 2014 May;44(5):1736-44. doi: 10.3892/ijo.2014.2311. Epub 2014 Feb 27. PubMed PMID: 24585004. 
17. Cohen S, Mosig R, Moshier E, Pereira E, Rahaman J, Prasad-Hayes M, Halpert R, Billaud JN, Dottino $P$, Martignetti JA. Interferon regulatory factor 1 is an independent predictor of platinum resistance and survival in highgrade serous ovarian carcinoma. Gynecol Oncol. 2014 Sep;134(3):591-8. doi: 10.1016/j.ygyno.2014.06.025. Epub 2014 Jul 1. PubMed PMID: 24995581.

18. Miše BP, Telesmanić VD, Tomić $S$, Šundov D, Čapkun V, Vrdoljak E. Correlation Between E-cadherin Immunoexpression and Efficacy of First Line Platinum-Based Chemotherapy in Advanced High Grade Serous Ovarian Cancer. Pathol Oncol Res. 2015 Apr;21(2):347-56. doi: $10.1007 / s 12253-$ 014-9827-1. Epub 2014 Aug 11. PubMed PMID: 25108408.

19. Miyamoto $M$, Takano $M$, Iwaya $K$, Shinomiya N, Goto T, Kato M, Suzuki A, Aoyama T, Hirata J, Nagaoka I, Tsuda $\mathrm{H}$, Furuya K. High-temperature-required protein $\mathrm{A} 2$ as a predictive marker for response to chemotherapy and prognosis in patients with high-grade serous ovarian cancers. $\mathrm{Br} \mathrm{J}$ Cancer. 2015 Feb 17;112(4):739-44. doi: 10.1038/bjc.2015.1. Epub 2015 Jan 27. PubMed PMID: 25628093. 